\title{
The Spectator Bias in the Linguistic Descriptions of Information Structure
}

\author{
Borchmann, Simon Uffe
}

Published in:

Language Sciences

DOI:

10.1016/j.langsci.2018.06.006

Publication date:

2019

Document Version

Peer reviewed version

Citation for published version (APA):

Borchmann, S. U. (2019). The Spectator Bias in the Linguistic Descriptions of Information Structure. Language Sciences, 76(nov). https://doi.org/10.1016/j.langsci.2018.06.006

\section{General rights}

Copyright and moral rights for the publications made accessible in the public portal are retained by the authors and/or other copyright owners and it is a condition of accessing publications that users recognise and abide by the legal requirements associated with these rights.

- Users may download and print one copy of any publication from the public portal for the purpose of private study or research.

- You may not further distribute the material or use it for any profit-making activity or commercial gain.

- You may freely distribute the URL identifying the publication in the public portal.

Take down policy

If you believe that this document breaches copyright please contact rucforsk@kb.dk providing details, and we will remove access to the work immediately and investigate your claim. 


\section{The spectator bias in the linguistic descriptions of information structure}

Simon Borchmann

\section{Introduction}

This article argues that the linguistic descriptions of information structure are biased. The argument takes a starting point in the observation that these descriptions are insufficiently informative and misleading when applied to language use embedded in practical activities, e.g. rifle hunting, brewing beer, playing handball, molding a foundation or landing an airliner. The purpose of the article is to explain these inadequacies and lay the groundwork for new informative and accurate descriptions.

The claim is that the observed inadequacies can be explained by a bias. This bias can be described on the basis of a distinction between two ways of looking at language: language use as an independent activity and language use as embedded in an activity. The former perspective implies that language use is separated from the activity that the speaker/writer refers to and can be analyzed as an independent activity with its own purposes, functions and structures. The latter implies that language use is part of an activity and must be analyzed as a contribution to the performance of the activity. Each of these views is associated with a set of assumptions about language and language use. The claim is, then, that the linguistic descriptions of information structure is based on the former perspective and that the assumptions associated with this view impose a bias in the analysis of natural language information structure. This bias is called the spectator bias.

Linell $(1982 ; 2004)$ argues that there is a written language bias in linguistics. The description of the bias is based on an impressive overview of linguistic tradition and different linguistic disciplines and approaches, and certainly, there are a number of points where the written language bias and the spectator bias coincide, not least the assumption that the semantic structure of the basic linguistic unit is that of a predication. However, the spectator bias also differs from the written language bias in that it is not related to the medium. Thus, the spectator bias leads to as inadequate descriptions of written language as of spoken language. It is therefore the claim that the spectator bias is a relevant supplement to the written language bias as regards an adjustment of the linguistic descriptions of information structure. 
In section 2 of the article, I will define information structure and identify the common features of the linguistic descriptions of information structure. In section 3, I will define the area of language use that forms the basis of the observations and illustrate a systematic discrepancy between the descriptions of information structure and this area of language use. In section 4, I will provide an explanation of the discrepancies. Firstly, I will consider the written language bias as an explanation, then I will outline a bias that can explain the discrepancies and, as I claim, characterizes the linguistic descriptions of information structure. In section 5, I will outline an alternative to the spectator bias. Section 6 contains concluding remarks.

\section{The linguistic descriptions of information structure}

\subsection{What is information structure?}

The term information structure covers the possibilities that a speech community makes available for indicating differences in the status of the information a speaker shares with a listener by means of an utterance. The term was introduced by Halliday (1967:200) and implies that an utterance is organized into information units that differ in status with regard to informativeness, and that the differences are formally marked. Other terms for this aspect of language use are psychological structure (Gabelentz 1869), thematic structure (Mathesius 1975/1961) and information packaging (Chafe 1976). The starting point of descriptions of information structure has been that information status is independent of constituent structure and semantics. In the early descriptions (Gabelentz 1869; Paul 1898), the differences in information status were considered as being psychological. In later descriptions, they have been described in terms of discourse (Weil 1978/1887; Mathesius 1975/1961), communicative dynamism (Firbas 1964; 1974; 1992), communication (Chafe 1970), text (Halliday 1994; Halliday \& Matthiessen 2014), cognition (Talmy 2000), and presupposition (Jackendoff 1972), to name a few. A general trend in the more recent descriptions is an increased awareness of how information structure affects the meaning of a discourse. Two directions of development can be identified. In formal approaches, it has been pointed out that information structure is integrated in semantics (Jackendoff 1972; von Heusinger 1999). These approaches have concentrated on the indications of information structure that affect the truth conditions, for example stress (indicated in capital letters), combined with particles:

(1a) John only introduced BILL to Sue. 
(1b) John only introduced Bill to SUE.

If John introduced Bill to Sue and to Mary and performed no other introduction, (1a) is true and (1b) is false. If John introduced Bill and Bob to Sue and performed no other introductions, (1b) is true and (1a) is false (Rooth 1985).

In informal approaches, the assumption that information structure is independent of semantics has been maintained. However, it has been pointed out that the information structure relates to the knowledge and beliefs of the listener/reader and influences the listener's/reader's interpretation, including strategies, expectations and inferences (e.g. Haviland \& Clark 1977; Prince, 1981, Reinhart 1981; Togeby, 1993). This can be illustrated by the following example:

\section{(2a) Jeff Parrot taler i lokale 316. Beklager.} // Jeff Parrot speaks in room 316. Sorry.

This sequence of utterances appeared on a piece of paper taped to the entrance door of the Department of Scandinavian Language and Literature, Aarhus University some years ago. The text was written by the organizer of the Parrot lecture, and quite remarkably in relation to social norms and values, it could be interpreted as a rather unpleasant welcome. This interpretation is based on the presumption that the first utterance provides information about the lecturer, Jeff Parrot, and that the regret is related to the fact that he is speaking. This can be considered the default interpretation when the information structure of the first utterance is like it is. However, there is no doubt that the intention of the writer was to provide information about the room number, and that the regret was related to a change of room number and the confusion it might have caused. It is also very likely that the readers understood that this was the intended meaning. From an information structural point of view, one could nevertheless argue that the writer did not make use of the possibilities that the speech community makes available to eliminate the unwanted interpretation. This could have been done, if the writer had organized the information units of the first utterance in the following way:

(2b) Det er i lokale 316 Jeff Parrot taler. Beklager.

// It is in room 316 Jeff Parrot speaks. Sorry.

In the understanding of (2b), the regret relates to the room number. One can only guess whether the organizer would have marked the status of the information unit 316 prosodically if he had spoken (2a), but this is at least possible. Thus, the example also illustrates that written language is less resourceful than spoken language with regard to the indication of differences in information status, and that there are crucial differences in speech and writing as a tool for sharing information. For the 
same reason, some descriptions of information structure have concentrated on intonation as a means of indicating differences in information status. Other descriptions have included indications that can be realized in written language, e.g. determiners, inflections, the order of words and phrases, constructions and particles. The point in this context, however, is that these later descriptions assume that information structure - regardless of whether we are dealing with speech or writing plays an important role in language comprehension and affects meaning.

Rather than looking at the two directions as being in opposition to each other, one can say that they each have a different information status as object, namely contrast that has an operator-like function, and rheme that has a salience-oriented function (Vallduvi \& Vilkuna 1998). Contrast marking is not frequent in everyday language use; thus, in some exchanges of information there are no contrast markings at all. Therefore, formal descriptions have a limited explanatory value for language comprehension in general. Rheme, on the other hand, principally occurs in any utterancebased sharing of information, and while it is a wider and vaguer concept than contrast, it has a substantial potential for everyday language understanding, for example the interpretation of example $2 \mathrm{a}$ as an unpleasant welcome. Accordingly, the majority of the linguistic descriptions of information structure have concentrated on this function. Therefore, it is the descriptions of salience-oriented function that I will concentrate on in this article.

\subsection{Information structure: first-order languaging or second-order language?}

A relevant question regarding the bias discussion and pertinent to the discussions that have been conducted in Language Sciences concerns the ontological status of linguistic structure. Thibault (2011) suggests a distinction that can serve as a basis for answering this question. The distinction is based on the distributed language view and should be considered as an alternative to Saussure's distinction between language and parole. Language is considered a "radically heterogeneous phenomenon that is spread across diverse spatiotemporal scales ranging from the neural to the cultural" (Thibault 2011), and the distinction related to this view is a distinction between first-order languaging and the second-order language:

First-order languaging refers to the organization of process on different scales that takes place when persons engage in talk together. Text and talk are radically different phenomena. Firstorder languaging crucially involves synchronized interindividual bodily dynamics on very short, rapid timescales of the order of fractions of seconds to milliseconds. (...) First-order languaging is a whole-body sense-making activity (Thibault 2011:214)

Second-order language comprises: 
patterns (...) that guide and constrain first-order languaging (...) stabilized cultural patterns on longer, slower cultural timescales (Thibault 2011: 216).

higher scalar patterns that function to differentiate or partition the environment in culturally salient, value-weighted ways (Thibault 2011: 220).

This distinction dispenses with the idea of langue as a prerequisite for parole and the related focus on language as a system. The dependency relation between langue and parole is reversed so that first-order languaging is regarded as the driving force in the formation of patterns and the primary object of language sciences. Accordingly, the focus of a linguistic description must be on "how dialogically coordinated first-order languaging is enacted and created in human activities that are spread across a diversity of timescales" (Thibault 2011:211). Second-order language is described on evolutionary grounds and with reference to Gibson's ecological theory of perception. Variations in vocalization at the level of populations afford increasingly semantically salient differentiations, while the populations' interactional needs and motives exert pressure in the direction of increased semantic differentiation. These processes give rise to a possibility space of virtual patterns that differentiate the environment in value-weighted ways and can be detected and enacted in first-order dynamics (Thibault 2011:217). Second-order language thus has a different ontological status than is assumed in the structuralistic descriptions in continuation of Saussure. It is not an abstract system or an idealized capacity, but virtual patterns resulting from first-order dynamics and which can only be registered at the level of populations. Thus, it corresponds to what Harder (2010) calls langue in the niche, i.e. language as an aspect of community life (Harder 2016).

We can now consider whether indications of differences with regard to the informativeness of two or more information units are a dynamic on very short, rapid time scales or patterns on larger time scales that guide and constrain languaging. The answer is probably that they are both. Thus, degrees of prominence (Chafe 1994) and expression focus (Krifka \& Musan 2012) seem to be a first-order organization; it takes place on very short time scales, may affect any part of an intonation unit and is understood in conjunction with gestures and other bodily dynamics. However, there is no doubt that the linguistic descriptions of information structure have concentrated on what Thibault considers to be second-order language. Thus, the difference between (2a) and (2b) is a difference between relatively stable patterns in Danish: a noncleft sentence and a cleft sentence. Therefore, I will concentrate on such relatively stable patterns in this study, and I will treat the descriptions of them on the premises of descriptions of second-order language. This means that the inadequacies I will point out are not considered to be a consequence of them being descriptions of second-order 
language, but of a selection bias. In other words, I acknowledge the efforts to describe and explain stable patterns or "structures" (Linell 2004; Harder 2010; 2016; Thibault 2011). As Harder notes:

structure has traditionally been understood as being inherent, underlying, and Platonic - more basic than actual usage. Hence, if you (rightly) believe that actual usage with all its variation is the most basic manifestation of language, you almost automatically tend to reject a structurebased description. However, once it is realized that structure serves to (partially) organize usage, rather than constituting an abstract ideal order, this fallacious inference loses its foundation. (Harder 2010:298-299)

What is crucial is that the basis for the descriptions of structures is a real population, and that the explanatory framework is the population's needs and motives.

I will include speech as well as writing and radio transmissioned speech in my observations. If you study language in human activities, it becomes clear that written language plays a crucial role in differentiating the environment in value-weighted ways, and that writing and reading interact with speaking and listening and extra-communicative actions. This applies not least to the activities that the cognitive counterpart to distributed language, distributed cognition (Hutchins 1995A), has focused on. In ship navigation, the use of written language such as bearing record logs and hoey position plotter values interacts with recorder's and plotter's speech and the quartermaster's regulation of the ship's course (Hutchins 1995a: 233-234). In landing an airliner, the use of written language such as speed cards and airspeed indicator values interacts with pilots' spoken cross checks of speedbug settings, the flap calls of the pilot who is flying and the movements of the flaps handle by the pilot who is not flying (Hutchins 1995b: 275-278). Similar interactions are seen in professional road cycling (Borchmann 2015). During pre-race tactics meetings, sports directors and riders read written weather forecasts on cell phones and discuss verbally how the information shared by means of the forecasts should be interpreted as specifications of affordances on the basis of route maps. This interaction is motivated and organized by the riders' need for selecting and coordinating positions in the peloton, and the interaction affects the riders' struggle for positioning during the race. Similar relations can be observed in the above three activities between speech, on the one hand, and extra-communicative actions and radio transmitted speech (intercom or VHF), where language users have no access to bodily dynamics like gaze, gestures, shifts in posture, on the other. Thus, if you ignore written language or radio transmitted speech in the study of languaging, you will lose explanatory value both for the organization of speech and for the interaction between speech and extra-communicative actions, such as a pilot's movement of a flaps 
handle or a road cyclist's struggle for positioning in a peloton (see also Goodwin \& Goodwin 1998:66-68).

When I use the term language use, it is not for manifestations of an abstract system or for the performance of an idealized competence, but for a verbal pattern-based sharing of information understood as a culturally salient, value-weighted differentiation of the environment (Borchmann 2018; Gibson 1979; Hodges 2009; Reed 1996), for example a group of people's sharing of the room number 316 that differentiates room 316 with all the affordances it entails, from room 318 (see example 2a). Such processes are mediated by writing as well as speech. In the case of writing, it is the understanding that constitutes the sharing. It should therefore be noted that when I use the term language use in relation to written language, it covers the reader's actions. Since writing can address a wide range of language users across cultures and values, it means that there can be different criteria of understanding from reading to reading (see also Raczaszek-Leonardi 2008:667). A mason will pick up other information from a weather forecast than a cyclist. What is decisive, however, is not that the criteria are the same from reading to reading, but that there are intersubjective criteria for understanding.

I use the term language use to emphasize that I focus on an aspect of languaging, namely stabilized cultural patterns that function to differentiate the environment in culturally salient, valueweighted ways. One can add that Thibault (2011) himself relies on descriptions of second-order language in the analysis of languaging. And, in fact, the description of information structure that Thibault relies on, namely Halliday's (2004) theme-rheme analysis, is among those that prove inadequate when applied to language use in practical activities.

As descriptions of second-order language, linguistic descriptions of information structure associate specific verbal patterns in language use with specific differences in information status and related communicative functions. This makes it possible to test the descriptions. In the following, I will extract such associations of patterns and statuses in the linguistic descriptions of information structure in order to test them on a concrete material.

\subsection{Common assumptions in the established descriptions of information structure}

As suggested in section 2.1, there are different linguistic approaches to information structure, and even within each of these approaches there are a number of different analyses and stratifications. Nevertheless, it is possible to point out a set of common assumptions. In the 
following I will identify a small set of assumptions that characterizes the linguistic descriptions of information structure.

The overall framework for the descriptions is that information structure is realized by main clauses formally marked as assertive speech acts, and that information structure, except for special, marginal functions, is independent of semantics. Information structure, thus, is typically illustrated by a variety of main clause patterns having the same truth conditions (see for example Chafe 1976:27; Halliday \& Matthiessen 2014:81; Mathesius 1975/1961:85; Talmy 2000:77), e.g. (examples from Gundel 2012: 585):

(3a) Smith won that election

(3b) This election was won by Smith

Information structure, then, is explained in terms of saliency. Within this framework, it is generally agreed that a main clause can be analyzed in two parts: a part identifying what is being communicated about, and a part conveying information about the identified object. In (3a) "Smith" identifies what it being communicated about, and "won that election" conveys the information communicated. In (3b) "This election" identifies what is being communicated about, and "was won by Smith" conveys the information communicated. In some descriptions the object communicated about is considered the most salient; in others the most salient is the information communicated. There are a number of finer analyses, but this analysis is basic.

A variety of terms have been used for the two parts, e.g. psychologische Subject-psychologische Prädikat (Gabelentz 1869), point of departure-goal of discourse (Weil 1978/1887), theme-rheme (Daneš 1974), old-new (Chafe 1970), topic-focus (Hajicova \& Sgall 2004), and topic-comment (Reinhart 1981). In the following, the part identifying what is being communicated about is called the topic-part and the object identified the topic. The part that conveys information about the topic is called the comment. There are different topic-part criteria within the linguistic descriptions of information structure. However, it is generally agreed that the topic-part is referential (Gundel \& Fretheim 2005). That is, with the topic-part the speaker/writer refers to an entity (or a mental representation of an entity). This criterion is based on the assumption that the predication is the basic unit of information. A simple predication is a combination of a reference to a particular entity, e.g. "Smith", and a general term, e.g. win. The combination entails that the particular entity referred to exemplifies the general term, i.e. possesses the property, belongs to the class or performs the role that the general term specifies (Strawson 1974). This semantic analysis is the basis for claiming that the only possible topic-parts in (3a) and (3b) are "Smith" and "the election". 
In many descriptions, group/class of entities has been added to entities (Gundel 2012). This addition is based on the assumption that the relation 'exemplify' is reproduced on higher levels of abstraction (Strawson 1974). That is, if the speaker/writer refers to a group or class of entities (or a representation of a group or class of entities) with the referential constituent of the predication, the referent will still exemplify a (more) general term. Thus, clauses with generic grammatical subjects are also considered to be predications (Lyons 1977).

There are various descriptions of the linguistic realization of the topic-part, but it is commonly assumed a) that an information-conveying utterance has one and only one topic, b) that the topicpart is grammatically marked and c) that the grammatical subject is the unmarked topic-part in a number of languages, including English and Danish. This assumption is the basis for the claims that the topic of (3a) is Smith, and that the topic of (3b) is the election. There are other topic-part indicating devices, but grammatical subject is one of the most frequently mentioned.

Within the salience-oriented descriptions, attention has been devoted to the role of the information structure in the establishment of coherence. The sheer quantity of the information structure variations that a speech community makes available for a speaker/writer indicates that sharing information is a significantly more complex process than has been assumed in code-based accounts of communication (Shannon \& Weaver 1998/1949). In line with this, it has been assumed that communication relies on a common ground (Clark 1996; Krifka 2008; Stalnaker 1974), i.e. the knowledge, beliefs and presumptions that speakers/writers assume they share with the listener/reader at any given time during the communication, and that it requires an active listener/reader who prioritizes information and adds information to the common ground based on the speaker's/writer's indications of information statuses.

The studies of the role of information structure in the establishment of coherence have been based on the predication-based topic-comment analysis. In line with this, the common assumption in these studies is that reference is the basic means for achieving coherence. On the basis of this assumption, a limited set of utterance patterns has been stipulated. Thus, it is claimed that continuous topic is the basic way - or one of the basic ways - of achieving coherence (e.g. Daneš 1974; Reinhart 1980:173; Geluykens 1999:36; Ulbæk 2013:76) e.g. (example from Daneš 1974):

(4) The Rousseauist especially feels an inner kinship with Prometheus and other Titans. He is fascinated by any form of insurgency 
What enables the establishment of coherence according to these descriptions is that the writer with the second utterance refers to entities in the common ground. The role of information structure, then, is to guide the referential inference that establishes coherence. By assuming that "The Rousseauist", rather than "Prometheus", is the topic-part, the reader can solve the referential inference that the anaphor "He" requires.

Another pattern is based on the assumption that topics, insofar as the topic-part is referential, must be a part of the common ground. Therefore, topics have to be introduced before information can be conveyed about them (e.g. Gelyukens 1999; Krifka \& Musan 2012; Mathesius 1975/1961; Togeby 2003). The principle that topics have to be introduced into common ground forms the basis of the following stipulated utterance pattern (example from Lambrecht 1994, see also Daneš 1974; Dik 1989; Halliday \& Matthiessen 2014; Hansen \& Heltoft 2011; Mathesius 1975/1961):

(5) Once there was a wizard. He was very wise, rich, and was married to a beautiful witch. In this sequence, the first utterance introduces a referent into common ground. The subsequent utterance, then, conveys information about the referent. What characterizes the first utterance in this pattern is that the grammatical subject is non-referential. The observation of such utterances has formed the basis of a distinction between two utterance functions. Thus, based on Brentano and Marty's distinction between thetic and categorical judgments (Brentano 1925; Marty 1940), the established descriptions of information structure distinguish between thetic and categorical utterances (Haberland 2006). Thetic utterances are characterized by the grammatical subject being non-referential. These utterances are therefore considered to be topic-less (Hansen \& Heltoft 2011; Kuroda 2005; 1972; Lambrecht 1994; Rosengren 1997; Sasse 1987;); their function is not to categorize, but to introduce a referent into the discourse representation (Lambrecht 1994) or to assert the existence of a state of affairs (Sasse 1987). Likewise, the utterance is characterized by having all-new character (Kuno 1972; Lambrecht 1994; Rosengren 1997) or by being logically unstructured (Kuroda 2005), that is, one cannot distinguish between the cognitive or the logical status of the information units in the utterance.

These associations of patterns, statuses and functions can now be applied to a set of utterances.

\section{Systematic discrepancies}


In this section I will show that there are systematic discrepancies between the linguistic descriptions of information structure and language use in practical activities. First, I will define the area of language use that the observations are based on. Then, I will apply the common assumptions of the linguistic descriptions of information structure to a selection of examples of language use.

\subsection{Activity-embedded language use}

The observations presented in the article are based on activity-embedded language use. Activityembedded language use is language use that forms part of the performance of activities. An activity is defined as an "organization of tool-mediated solutions of tasks in order to obtain an intended outcome and realize specific values" (Borchmann 2016; 2018), e.g. rifle hunting, spearfishing, baking bread, smoking meat, bricklaying, playing handball, driving a rally stage or landing an airliner. The definition is based on Hodges \& Baron's term value (1992) as accounted for in Hodges (2007). Values are: "the boundary constraints on ecosystems that define their dynamics and the directedness of organisms' activities within them" (Hodges 2007:590). The term tool-mediated origins from Vygotsky (1978) and covers the mutual dependency between tools and activities. On the one hand, the activity determines the structure of the tools; on the other hand, the tools enable the activity and contribute to the development of it. In this analysis, second-order patterns are considered to be tools for sharing differentiations of the environment. The term task implies a firstperson perspective on actions and events: actions and resources for action are considered relative to the specific tasks that perceiving-acting cognitive agents are faced with (Wilson \& Golonka 2013).

The phrase embedded signifies three conditions. Firstly, the language use can contribute to the realization of the values that guide the activity and to the likelihood of an intended outcome. This implies that the language use is action-guiding (Malinowski 1969/1923). Secondly, the listener/reader participates in the activity, the outcome of which can be affected by the language use. This implies that there are extra-communicative criteria of understanding (Wittgenstein 1968/1953), namely the act that an utterance as action-guiding language use suggests. Notice that the speaker/writer does not have to participate in the activity; a meteorologist who communicates a weather forecast participates in the activity of weather forecasting; but the listeners/readers of the weather forecasts can participate in a variety of other activities - bricklaying, road cycling, spearfishing etc. Thirdly, the listener/reader has activity-specific needs for information, and it is these needs that motivate the listener's/reader's involvement in the language use and guide the understanding of utterances. This implies that the common ground as a joint attentional frame that 
comprises what the participants typically find salient and interesting, is prior to the language use (Tomasello 2008).

In section 5, it will appear why this delimitation is of fundamental importance. For the moment, the delimitation serves as an instrument in the selection of language use that forms the basis of linguistic observation; the language use must meet these criteria.

\subsection{Systematic discrepancies}

In the following I will apply the linguistic descriptions of information structure to six examples of language use. The examples come from language use embedded in activities and are systematically selected with regard to the common assumptions of the linguistic descriptions of information structure. Thus, they include a main clause with non-referential grammatical subject (6), a main clause with a generic grammatical subject (7), a holophrase (8), a short form (9), a main clause with a verb in the imperative form (10) and two sequences of utterances (10 \& 11). All the examples are model examples of language use in activities in the sense described above. Below, each of the examples will be a) analyzed as activity-embedded language use, b) related to the common assumptions within the linguistic descriptions of information structure and c) accounted for as an indication of the inadequacy of these descriptions.

The following utterance is part of the activity rifle hunting:

(6) Med en 100 grains Oryx er der en afdrift på $44.3 \mathrm{~cm}$ ved $5 \mathrm{~m} / \mathrm{s}$ på 300 meter. // With a 100 grains Oryx there is a drift of $44.3 \mathrm{~cm}$ by $5 \mathrm{~m} / \mathrm{s}$ at 300 meters. (Rifle hunter to fellow hunters, diagnosis, www.jagtdebatten.dk 11 April 2012)

It occurs in a discussion on the internet in continuation of a hunting report in which a rifle hunter writes that he has shot two roe deer at 340 and 470 meters, respectively. Shooting at these distances carries a high risk of wounding the game, and this is incompatible with one of the values that guides the activity, namely the value the participants call "human"(humane). This value requires that you minimize the risk of wounding. For that reason, the hunter's behavior becomes the subject of verbal condemnation and regulation. (6) is uttered by another rifle hunter and is an action-guiding diagnosis of the two shots. With the utterance it is communicated that if the bullet weight is 100 grains, the bullet type is Oryx, the crosswind speed is 5 meters per second and the distance is 300 meters, then the wind drift is $44.3 \mathrm{~cm}$. Utterances like these contribute to the solution of the task of aiming and thereby to the likelihood of the intended outcome of killing an animal. It implies that a 
riffle hunter must compensate $44.3 \mathrm{~cm}$ on the horizontal axis. An experienced rifle hunter, however, knows that it is virtually impossible to determine the wind speed accurately over the entire range and thus, impossible to predict the wind drift accurately. In line with the value that guides the activity the utterance therefore specifies an obstacle for shooting. And the criterion of understanding is that the reader refrains from shooting under the specified conditions - and all the more at 340 and 470 meters.

According to the established descriptions of information structure, example 6 is a thetic utterance and, thus, topic-less. It does not establish an aboutness-relation and, thus, does not convey information about anything. Allegedly, the function is to introduce a referent into the common ground or to assert the existence of a state of affairs. Likewise, we should not be able to distinguish between the cognitive or logical status of the six information units drift, $44.3 \mathrm{~cm}, 100$ grains, Oryx, $5 \mathrm{~m} / \mathrm{s}$ and 300 meters.

This is a remarkably uninformative and misleading description of (6). Drift is a well-established topic of communication within the activity because of the goals and the values that guide the activity. There is an extensive knowledge base about drift; communication about drift is standardized; and ammunition manufacturers specify the drift for their products according to the standards. The epistemic basis for (6), thus, is the following table issued by the manufacturer:

\section{Norma Oryx $100 \mathrm{gr}$}

\begin{tabular}{|c|c|c|}
\hline \multicolumn{3}{|c|}{ Winddrift in $\mathrm{mm}$ for a $5 \mathrm{~m} / \mathrm{s}$ cross wind } \\
\hline $\mathbf{1 0 0}$ & $\mathbf{2 0 0}$ & $\mathbf{3 0 0} \mathbf{~ m}$ \\
\hline 42 & 182 & 443 \\
\hline
\end{tabular}

Fig. 1 Wind drift table Norma Precision AB

In accordance with the fact that drift is a well-established topic of communication, drift has been mentioned several times in the debate prior to (6) and is mentioned several times afterwards. Furthermore, the variation is actually identified in the utterance by means of the conventional term "afdrift" (drift). Certainly, none of the readers doubt that the utterance conveys information about drift and hence, that the topic of the utterance is drift. That is, the utterance is not topic-less. Likewise, the function of the utterance is not to introduce a referent or assert the existence of a state of affairs, but to determine the state of a known variation in the environment under certain 
conditions. Finally, one can distinguish between the cognitive and logical status of the individual elements. The term "afdrift" (drift) identifies a limited set of possible states of a known variation in the environment, whereas the numeral " $44.3 \mathrm{~cm}$ " indicates a single, hitherto unknown state of the variation. Similarly, one can distinguish between the logical and cognitive status of the states 100 grains, Oryx, $5 \mathrm{~m} / \mathrm{s}$ and 300 meters, on the one hand, and the state $44.3 \mathrm{~cm}$, on the other. The former are optional, hypothetical states. The latter is determined by the former, and the writer commits himself to the fact that the latter state can be perceived if the former states can be perceived. Furthermore, the state indicated by the numeral " $44.3 \mathrm{~cm}$ " is the state to be shared by means of the utterance whereas the other indicated states are conditions for the states to be shared (Borchmann 2016).

Thus, the established descriptions are not only insufficiently informative in the analysis but also misleading in the characterization of the written utterance (6). This result is general as regards utterances that fulfill the established description's criterion of thetic utterances: When they form a part of activities, they typically specify a state of a known variation (Borchmann 2016). Thus, the topic of these utterances is an activity-specific bounded and structured variation in the environment, and the comment - or focus as I prefer - is the indicated state of the variation.

The next example is part of the activity of landing an airliner, more precisely the approach planning:

(7) okay braking action was fair except at the end it was poor (Approach to pilots, in-flight approach planning, Southwest 12488 December 2005)

The utterance is uttered by the approach controller in a radio transmission to the pilots upon request for a repeat. With the utterance the speaker communicates that the friction on a specific runway, and hence, how easy the aircraft can stop after landing, is fair in the touch down area and the middle of the runway, and poor at the end. The communication of this information is based on pilots reporting their assessments of the aircraft's ability to stop to the air traffic control after landing. That is why the utterance is in past tense. The last report is indicative of the current state. Braking action varies over time and from runway to runway, and the actual state is crucial for safety reasons because it determines whether the aircraft can stop within the runway. (In fact, the actual landing resulted in a runway overrun with the loss of a human life). Braking action reports contribute to the task of determining the landing distance and hence to the realization of the value safety. As a decision factor, the variation in braking action is related to a small set of other variations, among 
others the tailwind. At the time of the utterance, the tailwind component implied that a braking action report including $^{1}$ the term poor specified an obstacle for landing (NTSB 2007). The criterion of understanding of (7), thus, is that the listeners divert to another airport.

(7) is grammatically characterized by a generic grammatical subject. Thus, according to the established descriptions it is a predication. However, if you analyze the utterance in a participant's perspective, it is clear that the utterance is not a predication. Braking action is a bounded and structured variation, and the communication about braking action is standardized:

\begin{tabular}{|l|c|c|}
\hline Runway Condition & $\begin{array}{c}\text { Reported Braking } \\
\text { Action }\end{array}$ & $\begin{array}{c}\text { Factor to apply to } \\
\text { (factored) dry runway } \\
\text { landing distance* }\end{array}$ \\
\hline Wet Runway, Dry Snow & Good & 0.9 \\
\hline Packed or Compacted Snow & Fair/Medium & 1.2 \\
\hline Wet snow, slush, standing water, ice & Poor & 1.6 \\
\hline Wet ice & Nil & Landing is prohibited \\
\hline
\end{tabular}

Fig. 2 Reportable states of the variation braking action (NTSB 2007)

The term braking action thus covers a variation consisting of four possible states, ${ }^{2}$ and the paradigm comprises four corresponding terms [good, fair, poor/medium, nil]. A braking action report, thus, indicates one of these states and excludes the alternative states. These features suggest that it is misleading to analyze the utterance as a predication. First, what is identified by the grammatical subject "braking action" is not assigned to a class, category or role specified by a general term. What is identified is the most general in the sense that it includes the types of entities picked out by the predicatives "fair" and "poor". Secondly, the terms related to entities are not the subject-terms, but the predicatives "fair" and "poor". Notice, that it would also be misleading to say that the relation is reversed so that the unique entities picked out by the predicatives are placed under a general term; because they are occurrences of a predefined type, in a limited, predefined set of types. Thus, utterances like braking action is fine and braking action is bad are not information conveying utterances, but semantic errors. Finally, the relation between what is identified by the grammatical subject and the predicatives "fair" and "poor" is not characterized by inclusion, but exclusion: by picking out an occurrence of the state 'fair', the alternative states 'good', 'poor' and 'nil' are excluded; by picking out an occurrence of the state 'poor', the alternatives 'good', 'fair'

\footnotetext{
${ }^{1}$ Braking action reports less than good are classified according to the most critical term in South West Airlines' flight operation manual (NTSB 2007)

2 If the runway is dry, the state of the braking action is not reported.
} 
and 'nil' are excluded. That is, (7) is not a predication. To distinguish this semantic structure from the predication I have suggested the term specification (Borchmann 2016; 2018).

Example 9 appears on a road sign on Angeles Crest Highway, Los Angeles:

(8) ICY

(Road authority to driver, driving at Angeles Crest Highway, LA 15 January 2017)

(8) was (or could have been) read by a motorist on 15 January 2017. The utterance indicates that the friction between the road surface and the tire tread is low. Like example 6 and 7, it is actionguiding. It contributes to the task of controlling the speed and the steering of the car, and the criterion of understanding is that the driver adjusts the speed and steering inputs to the low friction. According to the established descriptions, the utterance is incomplete and characterized as elliptical, i.e. a reduction of the predication 'The road is icy'. If you consider this analysis and characteristic in a participant's perspective, however, it is misleading. Drivers attend to a set of action-guiding information in the environment; that is what characterizes them as skillful drivers (Rasmussen et al 1993; Gibson 1979). One action-guiding information in this set is the state of the variation in friction. Accordingly, utterances like the following appear in language use that is part of the activity of learning to drive a car:

Vejgrebet er vigtigt, fordi det er afgørende for, at bilen kan accellerere, bremses og styres

// The road grip is important because it is crucial for the car to accelerate to be braked and steered (Author of driving school theory book to driving student)

Utterances like this one support the training of the ability to attend to and differentiate the states of a variation in ways that are relevant to the selection and control of actions in the performance of the activity. Thus, the skillful driver will already attend to the variation grip in the sense that any indication of a significant change in grip will be perceived. In other words, grip is a part of the common ground in the communication between road authorities and drivers. Therefore, it is redundant to identify the variation; it is sufficient to indicate a state of the variation (see also Raczaszek-Leonardi 2008:660; Bühler 1965/1934:155-156). The discrepancy between these types of utterances and the established descriptions arises because it is assumed that the basic unit of information is the predication. If you analyze these types of utterances as specifications, however, they are not only pragmatically, but also semantically complete.

Example 9 is part of the activity road cycling: 
(9) Gentle breeze, $5 \mathrm{~m} / \mathrm{s}$ from north

(Weather forecaster to cyclist, route planning, Torrild 1 December 2017)

The sequence is read by a cyclist prior to training. It contributes to the solution of the task of planning the route. In this phase of the activity, wind speed and wind direction are decision factors. A road cyclist will - everything else being equal - ride out in the headwind and home in the tailwind. Hence, the current wind speed and wind direction is action guiding. In the present case the criterion of understanding is that the reader rides out to the north.

The sequence is part of the following text on the internet:

Today, Friday 01/12/2017

\begin{tabular}{c|c|c|c|c}
\hline Time & Forecast & Temp. & Precipitation & Wind \\
\hline $\begin{array}{c}09: 00- \\
12: 00\end{array}$ & & $0^{\circ}$ & $0 \mathrm{~mm}$ & $\lceil$ Gentle breeze, $5 \mathrm{~m} / \mathrm{s}$ from north \\
\hline
\end{tabular}

Here it becomes clear that the cyclist's use of language is active and selective; he seeks information that can satisfy the needs determined by the activity. In the present case, the cyclist only reads the words "Gentle breeze", "5 m/s" and "from north" as it is these words that indicate the differences that make a difference for him.

The linguistic forms gentle breeze, $5 \mathrm{~m} / \mathrm{s}$ and north provide information about the variations in wind force, wind speed and wind direction. These variations are not mentioned, but this is unnecessary inasmuch as the reader actively searches for information about these variations and is able to recognize the linguistic forms used to differentiate the states of these variations. Therefore, it is misleading to characterize them as incomplete. Each of the linguistic forms gentle breeze, $5 \mathrm{~m} / \mathrm{s}$ and north is part of a well-established paradigm used to differentiate the state of a bounded and structured variation. By choosing a linguistic form within the paradigm, all the other linguistic forms are excluded as non-informative. Thus, the three utterances "gentle breeze", "5 m/s" and "from north" are not predications, but specifications, and as such they are complete in every sense.

Example 10 comprises a main clause with the verb in the imperative form (example from Kristoffersen et al 2016):

(a) ja og der er masser af plads til jer $/ /$ yes and there is plenty of room for you

(b) og så skyd for helvede ude fra 
// and so shoot fucking hell from outside

(Handball coach to handball players, half-time talk, Nordsjælland 2016)

The use of clauses like (b) have not been analyzed in the established descriptions of information structure. However, as utterances that is part of activities it seems that they require an analysis. The utterance is part of the activity of handball. It is uttered by the coach to the players in a half-time talk. The utterance relates to the shooting position and contributes to the solution of the task of scoring goals. The criterion of understanding is that the players shoot from the specified position "ude" (outside), that is, outside the nine meter line. The utterance differs from example 6 and 7 in that the topic is not identified by a conventional term. But, as we have observed in examples 8 and 9 , it is not necessary to mention a variation that the performers of activities can be expected to attend to. And shooting position is a variation that skillful handball players attend to. With the utterance the coach indicates an intended state of this variation. Thus, even though the utterance has no topic-part, it has a topic, and it conveys information about a topic. However, the information structure is not predication-based, but specification-based.

Another observation that can be made on the basis of (10) concerns the idea of referential topicparts as a basic means of establishing coherence. Both (a) and (b) must be regarded as topic-less according to the linguistic descriptions of information structure, and therefore there is no basis for the establishment of coherence. However, the players have no doubt regarding the relation between the information shared by means of the two utterances. With (a) the trainer guides the players' attention to information in the environment that specifies an affordance, namely plenty of room: plenty of room affords shooting at the goal from outside the nine meter line. With (b) she encourages them to make use of this possibility for action. One might add that the coherence is, in fact, linguistically marked with the conjunction "så" ( $s o$ ); but the understanding of the specific relation between the variation in room and the variation in shooting position depends on an activityspecific knowing how. Referential topic-parts, thus, do not seem to have any particular role in the establishment of coherence.

Example 11 is part of the activity of learning to fly a glider. Each of the five utterances are uttered by the gliding instructor to the student glider pilot controlling the glider during a winch launch. In a winch launch the glider is pulled up in the air with a cable connected to a winch. A winch launch is a critical phase of a flight, partly because the pull force is fierce, partly because the plane is close to the ground. Attention and control of the aircraft's position around the three axes 
pitch, roll and yaw is crucial for safety reasons. Each of the utterances a, b, c, d and e in the sequence below is action-guiding with regard to the control around the pitch axis.

(11)

$(00: 00,00) \quad(($ The cable tightens, and the glider accelerates $))$

$(00: 07,45)$ ((The glider lifts off, airspeed is $70 \mathrm{~km} / \mathrm{h}$ and rapidly increasing))

$(00: 08,46)(($ Airspeed is $90 \mathrm{~km} / \mathrm{h}$, the student keeps the control stick in a forward position))

(a) $\quad(00: 08,68)$ og opad opad

// and upwards upwards

(b) $(00: 09,75)$ der er flyvefart

// there is flight speed

'we've got flight speed'

(c) $\quad(00: 11,92)$ opad

(d) $\quad(00: 12,64)$ op

// upwards

(e) $(00: 18,99)$ træk lidt mere

// pull a little more

$(00: 38,33)$ ((The cable releases))

(Gliding instructor to student glider pilot, winch launch, True airfield, 2017)

The pitch is controlled by forward and backward movements of a control stick between the legs of the pilot. In a winch launch the pilot must keep the control stick in a slightly forward position until the glider has gained flight speed. When flight speed is gained, and the glider lifts off, the pilot must increase the pitch by pulling the control stick steadily backwards. The instructor utters a, b, c, d and e because the student does not pull sufficiently on the control stick. The utterances, thus, contribute to the task of controlling the pitch. The criterion of understanding a, b, c, d and e, is that the listener pulls the control stick further backwards, thereby increasing the pitch of the glider.

According to the established descriptions, each and every utterance in the sequence is topic-less, either because it is grammatically incomplete, because the grammatical subject is non-referential or because the utterance is in the imperative form, and thus without a grammatical subject. Therefore, the sequence must be considered incoherent. In a participant perspective, this description is misleading. As we have observed in the analyses of the examples above, holophrases, thetic utterances and imperatives that form a part of the performance of an activity have a topic. The utterances a, c, $\mathrm{d}$ and e convey information about the pitch, and thus their topic is pitch. Utterance $b$ conveys information about airspeed, and hence the topic is airspeed. The variations pitch and airspeed are closely related, because you control the airspeed by controlling the pitch and because 
the pitch control depends on the airspeed in a winch launch. Thus, each and every utterance is related to the control of the variation in pitch.

Now, one might claim that the sequence $a, b, c, d$, e is coherent because the utterances relate to the same topic. Example 11, however, makes it clear that topic continuity has nothing to do with coherence. At least not coherence in a sense that has anything to do with meaning and understanding. The topic continuity in the example depends solely on the fact that the student does not solve the task of controlling the pitch appropriately with regard to the intended outcome of the activity and the values that guide the activity. That is, we cannot assess the coherence of the sequence independently of the extra-communicative course of action. The sequence is embedded in the activity, and the structure is determined by the task solution in relation to the intended outcome and the specific values that guide the activity.

To summarize: When the established descriptions of information structure are applied to a systematic selection of prototypical utterances that form a part of activities, discrepancies appear. In the next section I will consider an explanation of these discrepancies with a view to establishing a basis for an alignment of the linguistic descriptions of information structure.

\section{An explanation of the discrepancies}

The discrepancies we have observed above are systematic: they apply to all the selected utterances and sequences; they apply not only to the individual utterances and sequences, but to the types of utterances and sequences; and there is a pattern in the discrepancies. Based on the above selection and analysis, it is easy to point out the assumption that causes the discrepancies, namely that the structure of the basic unit of information is that of a predication and the associated assumptions that the topic-part is referential, and that reference is the basic means for establishing coherence. Indeed, the review of the established descriptions and the selection of utterances are designed to make the limitations of these assumptions as clear as possible. Singling out these assumptions, however, cannot, in itself, serve as an explanation. If we want to create a basis for an adjustment of the linguistic descriptions of information structure, we have to explain why the descriptions assume that the predication is the basic unit of information, that topic-parts are referential and that reference is the basic means for establishing coherence. 
In the following I will suggest an explanation. First, I will consider Linell's (1982; 2004) claim of a written language bias (henceforth WLB) as an explanation. WLB appears to have an explanatory value as it is associated with some of the assumptions that cause problems. However, as I will show, WLB also has some limitations as an explanation of the observed discrepancies. In continuation of this demonstration, I will therefore propose an additional bias that can explain the discrepancies and, as I claim, characterize the linguistic descriptions of the information structure. This bias is based on a distinction between two different relations between language use and extracommunicative actions.

\subsection{A written language bias?}

Linell's (1982; 2004) claim of a WLB implies that the models and theories of language are dependent on long-time traditions of dealing with writing and written language. The description of WLB is based on an overall distinction between two ways of looking at language: languages as structured sets of forms used to represent things in the world and language as meaningful actions and cultural practices, interventions in the world (Linell 2004:3). Both views are associated with a variety of assumptions about language and language use. WLB is characterized by the former, whereas the latter, according to Linell, is a viable alternative to WLB. See Linell (this issue) for an elaborate description of WLB.

Among the assumptions associated with WLB is the following: "The WLB assumption: (...) The semantic or logical structure of the basic linguistic unit (...) is that of a predication or proposition. (...) in a proposition, something is predicated of something else" (Linell 2004:85). This assumption corresponds to the assumption that characterizes the linguistic descriptions of information structure and causes the discrepancies we have observed above. WLB, thus, clearly has an explanatory value for the observations above. There are, however, some limitations of WLB as an explanation of the discrepancies. WLB implies that the assumptions are the consequence of an on-sided focus on written language and thereby that the bias is related to the medium. But the discrepancies we have seen above are the same when it comes to written language, e.g. example 6,8 and 9. Certainly, three examples are few, but they are occurrences of patterns that we find everywhere in activityembedded language use: maps, pacenotes, memos, timetables, instruments, controls, tools, checklists, manuals, recipes, departure boards, que system LED's, road signs, forecasts, legal texts, guides, doors, highways, runways, price tags, tickets, boardingcards, etc. In fact, it seems to be characteristic of written language use embedded in activities, that it is specifying rather than 
categorizing, and thus, that it supports the need for differentiation rather than for categorization (Borchmann 2018; Bühler 1965/1934:156).

As to written language use embedded in activities, it applies in general that the linguistic descriptions of the information structure are misleading. This cannot be explained by the assumption that the descriptions are based on written language use. Rather, it points out that the descriptions are based on a written language standard that does not include written language like the above. Without wishing to detract from the explanatory value that WLB has for a number of problems in linguistics, it does seem to be the case that the description of WLB is also based on a narrow standard of written language. This is apparent in the distinction between speech and writing that forms the basis of the description of WLB. According to this distinction, written language texts are "relatively explicit", "relatively autonomous" and "static" (Linell 2004: 21-22). But, as I will argue below, this does not apply to written language use in general.

Initially, I have to say that I am skeptical about the idea that language use may be more or less explicit. With concepts such as Bühler's (1965/1934) empractical speech and Wittgenstein's (1968/1953) language game, one can argue that any given language use - ceteris paribus - is exactly as explicit as it should be. If you claim that one pragmatic well-functioning language use is less explicit than another, your claim depends on projecting an ideal that entails that language reflects logical thinking and requires that all the information included in a process of understanding must be represented linguistically. And while these entailments are valuable in an epistemological context, they will not lead to informative and accurate descriptions of everyday language use in general. However, it may be meaningful to characterize a language use as terse or verbose, but this will always be relative to a norm. And the question is how we legitimize the application of a norm from one type of language use or genre to another type of language use or genre in a linguistic description of everyday language use. Let us, for the sake of the argument, assume that the norm we use as a standard in the assessment of the terseness of a language use is a sentence grammar. In this case, it is clear from the examples in subsection 3.2 that there is no difference between written and spoken language use as regards the terseness. Whether or not you can find such differences depends entirely on which type of language use or genre you choose. For example, if you take the written language in a motorist's environment, it is very terse. The language use that appears when I get into my car and turn the key are the following: "Sunday", "17.02.2018", "ODO $56252 \mathrm{~km} "$, "0", "10:21", "12345678 x1000 rpm ", " 20406080100120140160180200220240 km / h ", " Shift ", " L ", " R ", " Disp ", " Mode ", "CANCEL -SET + RES", "Passenger airbag on", "Temp", "A / C", 
"Radio", "Set", "Full", "FM DR P1", "CD in". When I start driving, the written language that appears in my field of view is the following: "P", "OK 9511.4992 11.46 Diesel 9.89", "Søkrogen 1-70", "445 Skanderborg 19", "40 Zone", "Krydsende cyklister" (cyclists crossing), "200m", "60"," Torrild 4 ", " Torrild 2 "," Torrild "," 223 "," 215 "," 193 " 161 "," 157 ". The spoken language during this ride, on the other hand, for example my wife and I discussing the culture in a soaring club, will be verbose. Likewise, if my wife and I stop our discussion and turn on the radio, the spoken language of the journalists, politicians and intellectuals participating in the program will comprise an abundance of words compared to the written language in the driving environment, and it will, indeed, be very close to the standard of a sentence grammar. The reverse, of course, is true if I compare Coetzee's Disgrace or The Cambridge Handbook of Expertise and Expert Performance with the spoken language of a co-driver in a rally car: "two fifty (0.9) five minus left over crest one twenty:: (4.1) one twenty (1.9) five minus right two hundred (5.1) four plus left into small cre:st (0.3) into four plus right leg small cut narrow exit" (Glenn Macneall stage 1, International Rally of Queensland 2016). Here, it is the written language use that is verbose and approximates the sentence grammar, whereas the spoken language use is terse. How terse or verbose a language use is, relative to a norm, has very little to do with the parameter spoken-written. If we should make a generalization that provides a basis for predicting the terseness of a language use, the relevant parameters are rather a) how well-developed and well-defined the language user's joint attentional frame is, including whether the speaker/writer may presume that the reader/listener is able to differentiate the environment in relevant ways and has specific needs for information, $b$ ) the amount of time and space available to the speaker/writer for speaking/writing, c) the amount of time available to the listener/reader for understanding and d) the task load on the listener/reader. Applying these parameters can explain why the written language use (8) and (9) and the spoken language use (11) and during rally driving are as terse as they are, and why my discussion with my wife, Coetzee's Disgrace and the written examples of language use in the linguistic descriptions of information structure (4) og (5) are as verbose as they are. But the point is this: If you claim that written language use is more explicit than spoken language use, this says more about the written standard you apply than about written language.

Similarly, written language use is not more autonomous than spoken language. As we have seen, written language use like (9) requires an active reader who selects some parts of the text rather than others and possesses a knowing how that enables him to understand the selected parts as information. This also applies to the written language in the cockpit of my car and on the road 
signs. For a considerable part of this language use, long-term practice-based learning is required for understanding. The reader must establish an attentional frame and an ability to differentiate the environment in relevant ways through practice in order to attend to and pick up the information shared by means of the written language use $80 \mathrm{~km} / \mathrm{h}$, for example, in terms of braking distance. Even the understanding of fictional prose - that serves as the basis for the idea of relative autonomy because it can be read hundreds of years after its release - is based on an active reader who attends to some parts of the text rather than others, employs his knowledge of the world and adds information to the linguistically represented information through knowledge-based inferences. In short: The idea that written language use should be relatively autonomous depends on the codebased account of communication (Shannon \& Weaver 1998/1949). And none of the descriptions I am concerned with subscribe to this account (see subsection 2.3).

Finally, written language use is not static, but dynamic. At least it is characteristic of texts that form a part of activities that they change continuously. This applies to screen-, board- and LEDbased communication and reporting systems, such as ACARS, departure screens, gasoline price boards and queue system LEDs. The information in the environment shared by means of the system, e.g. the dew point, the departure time, the gasoline prices and the number served, changes continuously, and the words change with them. On slightly larger time scales, weather forecasts on the internet, for example, are updated on an hourly basis or from day to day. And on even bigger time scales it applies to laws, instructions, manuals, guides and curricula. These change at more or less fixed intervals in the sense that a new text replaces the old. The replaced text may be available if it is printed, but it has lost its institutional support as a source of information. The reading of it, thus, can no longer be considered as sharing information, but merely a trace of it. For all of the above-mentioned examples of written language use, the information shared by means of them is determined by a communication-external dynamic. This dynamic can be more or less sluggish, and graphical artefacts may appear as a trace of a communication event long after the event has occurred, but this does not change the principle characteristic.

These observations indicate that the description of the WLB is characterized by a narrow standard of written language. It is possible that there are those who would not consider some of the examples of the written language mentioned above as communication, e.g. the numeral 80 on a speedometer scale. However, this occurrence is an intentional, convention-based, culturally embedded attempt to share information in the form of a value-weighted differentiation of the environment. And it is a prerequisite for understanding this occurrence that the motorist has grown 
up in the culture in which it exists and perceives the numeral as such an attempt. If it is claimed that this is not written language, this claim merely supports the statement concerning a narrow standard.

My point is not, of course, that there is no difference between spoken and written language. Surely, there are a number of significant differences (see subsection 2.1). The point is that the distinction between spoken and written language as described by Linell is based on a narrow standard of written language (and perhaps also outdated theories of communication). Indeed, Linell writes that the text type assumed in WLB is "expository prose" including "narratives" (Linell 2004: $23,39,65,101)$. Based on this assumption, WLB is insufficient as an explanation of the observed discrepancies. If we are to explain the observed discrepancies and point to an alternative basis, we must determine where this narrow standard comes from.

The claim that WLB is based on a narrow standard of written language is far from new. Thus, Linell (2004) defends the description of WLB by pointing out that it is WLB, and not the description of WLB, that is characterized by a narrow standard. This is a very reasonable defense, and in line with this, the observations in subsection 3.2 do in fact support Linell's description. The problem in relation to the observations presented in subsection 3.2, however, is that WLB does not explain why linguistics is based on a narrow standard of written language. In other words, the narrow standard cannot be explained by the medium - or at least not by the medium alone. Hence, there is a need for an additional explanation. In the next section I will suggest such an explanation.

\subsection{The spectator bias}

The main claim of this article is that the linguistic descriptions of information structure are characterized by what I call spectator perspective. Most importantly, the term spectator does not apply to the linguist's role; the linguist's role in the description of information structure must, of course, be that of an observer. The term applies to the users of the language that the linguist observes, and it implies that their language use is separated from the activities the speaker/writer refer to and constitutes and independent activity. The spectator perspective is associated with a small set of assumptions about language use. The set comprises three assumptions about the relation between language use on the one hand and extra-communicative actions and events on the other, and an assumption about an abstract, general purpose of language use. These assumptions impose a bias in the description of information structure. I call this set of assumptions the spectator bias. The spectator bias implies that the linguistic descriptions concentrate on language use that can serve the assumed purpose, that the descriptions must be informative in relation to the fulfillment of this 
purpose and that this purpose, thus, governs both the selection and the analysis of examples. This does not exclude that a description can include examples of language use that cannot serve this purpose, but in that case, they are few, they cause discrepancies in the analysis, and they are treated as exceptions that may be subject to special rules.

The four assumptions can be illustrated taking a starting in the following two examples from the established linguistic descriptions of information structure:

(12) mukashi mukashi aru tokoro ni ojiisan to obassan ga sunde-imashita. ojiisan wa yama e shibakari ni ikimashita.

Once upon a time, there was an old man and an old lady.

The old man went to the mountain to gather wood. (Hinds from Givon 1984)

(13) a búnch of us were hiking (from Chafe 1994)

The examples are chosen partly because they are prototypical of the language use described within the spectator perspective and include both written and spoken language, partly because both Givon and Chafe pay close attention to the empirical basis of linguistic descriptions. Thus, they are critical of approaches using unnatural data (Chafe 1994:16-17) or an artificially narrow range of language facts (Givon 1982:82), and they emphasize the necessity of using a broad range of natural language use - both spoken and written. Hence, the bias is not the result of the construction of data or the contemplation and analysis of decontextualized linguistic items (see also section 2.3).

The first assumption concerns the relation between the language use and the subject of the language use and the listener/reader role that this relation implies. Thus, the language use does not form a part of the activity that the speaker/writer refers to, and the listener/reader, thus, does not participate (or prepare the participation) in the activity that the speaker/writer refers to. This relation is typical of the literary language use of 12 . The language use does not form a part of the activity of gathering wood (shibakari), and the reader does not participate in the wood gathering. Quite remarkably, the same applies to the non-literary language use in the established descriptions. Example 13 is part of a sequence of utterances in which a woman tells another woman about a hike she has been on. Again, the language use does not form a part of the activity of hiking, and the listener does not participate in the activity of hiking. Nor does the listener prepare for a hike or participate in the activity of learning how to hike. Now, it is possible that the story about the hike has a function in the performance of the activity, and it is possible that the listener actually prepares for a hike. However, these relations are not accounted for in the analysis of the examples, and hence, the function of language use in relation to the performance of the activity is left undescribed. 
In other words, in the linguistic descriptions of information structure, language use is interpreted and analyzed independently of the activities that the language use refers to; understanding and the analysis of the language use do not depend on the participation in or the ability to perform the activity to which the language use refers. This first contextual relation is provisionally negatively defined. A positive definition is that the language use depicts activity and that the listener/reader is a spectator to the activity depicted.

The second assumption associated with the spectator perspective is closely related to the first and concerns relevance criteria. The assumption is that the relevance criteria that apply to the pickup and sharing of information in the performance of the activity that the speaker/writer refers to, do not apply to the language use. In gathering wood for a fire (see example 12), it is relevant to pick up and share information about moisture content, calorific value, length, thickness, volume, weight, distance, transportation method, etc. But that does not apply to the language use illustrated by example 12. A similar relation can be observed in the non-literary example of language use, 13 . Thus, during hiking or in preparing for a hike, it is relevant to pick up and share information about access to water, topography, weather conditions, available maps, scales, distances, speed, course, height, focal points, baggage weight, weight distribution, tightness of the hip belt, participants' physical shape, participants' current mental states etc. However, none of this applies to the language use in example 13. As Chafe remarks, specific information like the above will be "inappropriate" (1994:129) in the language use exemplified by 13, because it will bore the listener.

This negative description does not mean that there are no criteria of relevance in the spectator perspective. The criteria, however, are determined by something other than the activity that the speaker/writer refers to. Thus, the tendency in the spectator perspective is that it is the language use itself that determines the relevance criteria. In example 12 it is the introduction of the old man that makes it relevant to provide information about him; an introduction of an object into the common ground creates the expectation that further information will be provided about the object (Togeby 1993; 2003). In example 13 the relevance criteria are defined by "a narrative scheme" activated by the sequence, and in relation to this scheme, utterance 13 is relevant as something that provides "the background activity" (Chafe 1994:129). This tendency is closely linked to the third assumption.

The third assumption concerns the motive of the linguistic interaction. A hallmark of spectator language use is that it is not motivated by specific needs for information: the listener/reader has no prior need for information; the listener/reader does not participate in the interaction in order to satisfy such needs; the listening/reading and understanding is not guided by such needs; and the 
utterances and sequences are not adapted to such needs. This, of course, is a prototypical feature of literary prose like example 12; the reader's involvement in this language use is not motivated by a prior need for information about, for example, the weight or the moisture content of the wood gathered by the old man - or the old man for that matter. And the reading and understanding of the utterances are not guided by such prior needs. Rather surprisingly, the same applies to the nonliterary examples of language use in the established descriptions. Thus, the listener does not participate in the narrative interaction that (13) is taken from in order to get information about access to water, weather conditions or the scale of the available maps. In any case, it is not explicated in the analysis, and there is nothing in Chafe's analysis of the sequence that shows that the speaker adapts the utterances or the sequence to such information needs. A positive definition of the relation is that the need that motivates the listener's/reader's involvement in the linguistic interaction is related to a function rather than to information, for example, a need to be entertained, a need to establish or maintain a social relation or a need to be polite.

The relation between language use and activities that characterizes the spectator perspective can be summarized in one overall relation: the language use is separated from the activity the speaker/writer refers to and constitutes an independent activity, i.e. with its own purposes, functions and structures.

The fourth assumption that characterizes the spectator perspective is closely linked to the separation of language use and activity. In concerns the purpose of language use and can be formulated roughly as follows: The speaker/writer perceives, infers or imagines a particular action or event and depicts this action or event by means of an assertive speech act so that the listener/reader can form a mental representation of this action or event. In short, the purpose of spectator language use is to provide the listener/reader with a mental representation. Example 12 provides the reader with a mental representation of wood gathering. Example 13 provides the listener with a mental representation of a hike.

It should be noted that the assumption about the purpose of language use is not necessarily confined to representation. However, the spectator perspective implies that the fulfillment of other purposes is mediated by the representation so that the formation of a representation is a prerequisite for the understanding processes that the fulfillment of the other purposes requires.

The spectator perspective implies a preference for particular types of language. Thus, the prototypical language use in the linguistic descriptions of information structure is narratives. These can be analyzed as something that depicts activities. It is therefore tempting to call the spectator 
bias a narrative bias. However, as Klein (1999) shows, narratives can contribute to the performance of activities, e.g. in the evaluation of solutions to problems, and when they do this, they can fulfill all the conditions for activity-embedded language use. Hence, it is not the focus on specific types of language use that constitutes a bias, but the analytical perspective and the assumptions associated with this perspective.

The claim is that the established descriptions of information structure are characterized by the four assumptions described above, and that these assumptions impose a bias in the description.

4.3 The relation between the spectator perspective and predication, reference and coherence

In section 4.1, I have pointed out that the observed inadequacies cannot be explained by referring to the medium. Written language use is not generally characterized by the features that the basic unit of information is a predication, that topic-parts are referential, and that coherence is based on reference. The assumptions of these linguistic features, however, can be explained by the spectator bias. Thus, in the spectator perspective, there is a functional relation between these features and language use. Firstly, the assumption concerning the purpose of language use poses constraints on the pragmatic functions and hence on the semantic structures of utterances. In order to fulfill the purpose vis-à-vis the spectator, the language use must enable the formation of a representation of someone doing something. A contributing factor to the pragmatic function of utterances separated from the activity is that the listener/reader does not participate in the activity. Therefore it is necessary to refer to the participants in the activity. Thus, the functional constraint on semantic structure is that it contains the elements required for this function: an element that specifies a property, class or role and an element that indicates who possesses the property, belongs to the class or performs the role specified by the other element. This is precisely what the predication affords.

Secondly, the listener/reader has no activity-specific knowledge and therefore no activityspecific need for information. Therefore it is necessary to establish a common ground constituting a joint attentional framework that enables the understanding. This requires an abundance of words. Speakers/writers cannot confine themselves to satisfying specific needs for information like 'what is the grip?'; 'what is the wind speed?' or 'what is the wind direction?'. They must answer the open question: 'what happens?'. This is precisely what the predication affords.

Thirdly, the prototypical language use in the spectator perspective is narrative. Narratives typically comprise a small number of individuals constituting the main characters. Listeners/readers 
of narratives attend to main characters (Garrod 1995; Sanford \& Garrod 1994) insofar as they are spectators to the chain of actions and events that the main characters participate in. Thus, the language use must enable the listener to follow these characters through the chain of actions and events, and therefore the narratives must contain continuous references to the characters. This is the main contributing factor to the assumption that continuous topic is the basic way of achieving coherence.

Fourthly, in the spectator perspective the listener/reader has no activity-specific knowledge, and since the listener's/reader's ability to relate to activity-specific information is very limited, it is necessary to support the listener's/reader's attempt to create coherence. Thus, the common ground must be established linguistically, and coherence must be indicated linguistically. This is a contributing factor to the assumption that topics must be referred to and that references, and hence, referential topic-parts are the basic means of achieving coherence.

Hence, the spectator bias can contribute to an explanation of the fact that the linguistic descriptions of information structure assume that the structure of the basic unit of information is that of a predication, that the topic-part is referential, and that such topic-parts are the basis of coherence.

\section{An alternative to the spectator perspective}

In this section an alternative to the spectator perspective will be outlined. Initially, it must be emphasized that the aim of the alternative is not to provide a general framework for linguistic analysis, but a basis for solving the problems that have been presented in section 3.2. As we have seen in subsection 3.2, the problem is not related to the assumptions of specific verbal patterns; one can indeed observe patterns like so called "thetic sentences" and "ellipsis" in speech and writing used in the performance of activities. The problem is related to the information statuses and functions associated with the patterns. Thus, the aim is not to replace descriptions of "stabilized cultural patterns on longer, slower cultural timescales" with descriptions of "synchronized interindividual bodily dynamics on very short, rapid timescales" (see subsection 2.2). One cannot on the basis of the discrepancies shown in section 3.2 reject that there are stable relations between patterns on the one hand and information statuses and functions on the other. What one can claim is 
that the existing descriptions of these relations are not informative and accurate. The alternative shall provide the basis for informative and accurate descriptions of such relations.

The description of the spectator perspective identifies the assumption of language use as an independent activity as the main cause of the discrepancies. This indicates that language use must be considered as part of an activity. This approach is far from new. From the viewpoint of ethnographically based social anthropology, Malinowski (1969/1923) points to language in action, i.e. language use embedded in non-linguistic courses of action like hunting, fishing and tilling the soil, and claims that this language use is primary. From a psychological point of view, Bühler $(1965 / 1934)$ introduces the term empractical speech suggesting that utterances are integrated in an environment. From a philosophical point of view, Wittgenstein (1968/1953) proposes the concept of language games (Sprachspiel) to emphasize that speaking a language is part of an activity (Tätigkeit). The proposal is based on the private language argument: it is the non-linguistic behavior that accompanies the linguistic behavior that provides the criteria for understanding the linguistic behavior. Therefore, in order to learn a language it must be a part of an activity. However, Malinowski's, Bühler's and Wittgenstein's proposals have not had a bearing on the linguistic descriptions of the information structure.

There are new approaches to language where speech is considered to be a part of an activity (e.g. Clark 1996; Cowley 2009; Goodwin \& Goodwin 1998; Heritage \& Clayman 2010; Levinson 1979; Linell 2004, 2010; Pedersen 2012; Steffensen 2012; Thibault 2011). It is not the place to review these here; the distributed language view has been sketched out in subsection 2.1, and the basis for solving the specific problems are, in fact, already there in Wittgenstein's private language argument. However, to justify the particular focus of the alternative suggested below I will identify a possible limitation of some activity-oriented approaches in relation to the specific problems that the alternative addresses.

Levinson (1979) introduces the term activity type that covers: "goal-defined, socially constituted, bounded, events with constraints on participants, setting, and so on, but above all with constraints on the kinds of allowable contributions" (Levinson 1979: 367). The question Levinson tries to answer based on this definition is: "In what ways do the structural properties of an activity constrain (especially the functions of) the verbal contributions that can be made towards it?" (Levinson 1979: 370). Allegedly, Levinson's term includes both linguistic and extra-linguistic contributions. However, the structural properties of activities that Levinson concentrates on are exclusively properties of utterances. The verbal contributions are simply constrained by other verbal 
contributions. That is, language use in this perspective seems to have extricated itself from the activity and become an autonomous activity with its own constraints. Certainly, Levinson writes that it will be impossible to describe the function of utterances that form a part of a game without referring to aspects of the game; but this has no consequences for the analysis. This imbalance is particularly clear in Levinson's description of the following language use in basketball:
A: Alright Peter.
B: Lord!
C: Farewell people.
A: C'mon Peter.
B: Beautiful tip!
A: Right over here.

These examples are characterized as "massive ellipsis" (Levinson 1979: 366). Where the linguistic norm that makes this language use elliptical comes from is not stated. But it is not the activity. The perspective taken, thus, correspond to the perspective of the linguistic descriptions of information structure: language use is an independent activity with its own structures.

A similar imbalance can, in fact, be observed in Linell's (2004) alternative to WLB. The alternative differs radically from the spectator perspective on the general level. Thus, the assumption regarding the relation between language and activities is that communicative activities are embedded in human purposes (Linell 2004: 42-43) and that language must be explained in terms of extra-systemic factors, including "psychologically based processing constraints" and "various kinds of background knowledge about the world and non-linguistic or pre-linguistic experiences" (Linell 2004: 47). But on the specific levels of linguistic analysis, tendencies towards viewing spoken interaction as an independent activity do appear. Thus, the focus on these levels is the relation between utterances rather than the relation between utterances and extra-systemic factors. This applies among other to the analyses of sequences of utterances and information structure. According to the alternative to WLB, the following applies to the organization of spoken utterances:

The flow of utterances in spoken interaction is organised in terms of turn-constructional units (Linell 2004:66)

although utterances are built in an incremental fashion, there are dependencies between units in the structures of talk-in-interaction too. (Linell 2004:71)

Utterances are (...) acts (communicative acts, contributions to dialogue) by speakers in interaction with partners and contexts. (...) The linguistic means deployed are turn-constructional units reflecting speakers' orientations to various linguistic structures (Linell 2004:100) 
The activity analyzed is organized in speech units, not in speech units and extra-communicative acts. The dependency relation highlighted is a dependency relation between utterances. In line with this, utterances are considered to contribute to dialogue, not to solutions to extra-communicative, practical tasks. Finally, the linguistic means deployed reflect the speaker's attention to linguistic structures, not information in the environment relative to the listeners' or speakers' need for information at the current stage of the activity. The limitations of these assumptions are rather clear if we relate them to example 11. This sequence of utterances is truly embedded in an activity and cannot be explained without reference to extra-systemic factors such as the listener's solution to the practical task, non-linguistic experiences and the values and goals that guide the activity. There are no dependency relations between the utterances, but between the utterances and the listener's solution to the practical task of controlling the pitch relative to the intended outcome and the values of the activity. The speaker does not attend to other utterances, but to the information in the environment that serves as the extra-communicative criteria for understanding the utterance, in this case, the pitch of the glider.

In the alternative to WLB information structure is accounted for in the following way:

Utterances in spoken interaction have responsive (backwards-pointing) and projective (forwardpointing) aspects, i.e. inherent relations to other utterances (prior and projected next ones). The responsive aspects of many utterance types are formally marked (Linell, 2004: 68)

According to this description, information structure specifies relations between utterances. This corresponds to the descriptions of text patterns (see subsection 2.3) within the linguistic descriptions of information structure. Thus, the thetic utterance in example 5 (and example 12) is a prototypical example of the projective aspect. The dummy-subject "there" specifies an introduction of a reference to be followed by an utterance that predicates a property, class or role of the referent. This, however, is a prototypical feature of the narrative language use as it is analyzed in the spectator perspective. In activity-embedded language use the information structure of an utterance is adapted to the listener's knowing how and the related need for information at the current stage of the activity.

That is, although Levinson's approach and Linell's alternative to WLB provide a general framework for the analysis of activity embedded language use, there are tendencies towards a spectator perspective on the specific levels of linguistic analysis. The point is not, of course, that there no dependency relations between utterances. There are such relations in some types of language use, and it is relevant to describe them. The point is that there has been and still is a one- 
sided focus on such relations within linguistics, and that it is this one-sided focus that cause discrepancies in the analysis of activity-embedded language use. In other words, viewing language as "meaningful actions and cultural practices, interventions in the world" (Linell 2004:3) is not a solution to the specific problems in the linguistic descriptions of information structure if "meaningful actions and cultural practices" confine themselves to communicative activities (Linell 2010), and the "world" we intervene in, thus, is a world of communication. It should be added that Linell (2010) points to the fact that communicative projects are regularly embedded within a larger non-communicative projects. Nevertheless, the relations described within this framework are also primarily relations between utterances. An informative and accurate description of the information structure of utterances that form a part of activities requires a disclosure of the dependency relations between patterns in speech and writing, on the one hand, and extra-communicative actions, on the other. That is why the focus in the alternative is on these relations. The alternative suggested comprises the following four closely overlapping methodological constraints.

1) Language use is embedded in goal-oriented courses of extra-communicative actions (Malinowski 1969/1923). Therefore, the information statuses and the patterns that indicate differences in information status must be described in relation to such courses of actions, and on the basis of utterances that occurs in such courses of actions.

2) In the description of information statuses and the patterns that indicate differences in information status a participant perspective must be taken. That is, the statuses and patterns must be described based on the tasks that language users are confronted with in the performance of activities (Bühler 1965/1934, Wilson \& Golonka 2013). A preliminary assumption is that the general task under these circumstances is to pick up information in the environment in order to select and coordinate actions. 3) For each utterance one tries to describe with respect to its contribution to the formation of patterns, there must be external criteria for understanding in the form of an extra-communicative action (Wittgenstein 1968/1953).

4) The language use that forms the basis of the description of statuses and patterns must rely on an already established, well-defined joint attentional frame (Tomasello 2008). This implies that the listener/reader has a specific need for information prior to the language use, and the speaker/writer can be assumed to adapt the spoken and written utterances to such needs. 
In section 3.1, the delimitation of activity-embedded language use was presented as an instrument in the selection of material for observation. But it is precisely these four constraints that are contained in the delimitation. Thus, if the material meets the criteria of activity-embedded language use, the four constraints are satisfied.

A particularly important constraint is 3 . If this constraint is satisfied, it implies that the utterance is embedded in an activity, that the listener/reader participates in the activity and has specific needs for information, that the listener/reader differentiates the environment according to the goals and values that guide the activity and that the listener/reader share these goals and values. Hence, constraint 1,2 and 4 can be considered as specifications of the entailments of this constraint.

Constraint 2 and 4 point to the paramount weakness of the linguistic descriptions of information structure: The descriptions have cut themselves off from the need for information that motivates listener's and reader's participation in linguistic interactions, that guide their understanding of the utterances and that speakers and writers can be assumed to adapt their utterances to. This is fatal in a description of natural language information structure. ${ }^{3}$ The four methodological constraints above provide an in-depth remedy for this weakness.

Human non-communicative activities are the cradle of human communication (Tomasello 2008) because they give rise to a need for information and motivate the sharing of information in the selection and coordination of extra-communicative actions. Therefore, this seems to provide a good basis for a description of natural language information structure.

\section{Concluding remarks}

I have shown that the established descriptions of information structure are insufficiently informative and misleading as regards thetic utterances, utterances with generic grammatical subjects, holophrases, short forms, utterances with verbs in the imperative form and coherence of utterance sequences. I have suggested that these inadequacies can be explained by a spectator bias. In continuation of this suggestion, I have argued that an alternative to the spectator bias must enable a

\footnotetext{
${ }^{3}$ An indication of the awareness of this fundamental flaw in the linguistic descriptions of information structure is the method of constructing questions that an utterance may be the answer to in order to determine the rheme (or focus). This method can be considered as an attempt to bring the single most important factor back into the description: the listener's/reader's need for information. But, surely, it is not a solution to the problem, but a symptom of it.
} 
disclosure of the dependency relation between patterns in speech and writing, on the one hand, and extra-communicative actions, on the other. The argument is that the information needs that motivate listener's and reader's participation in linguistic interactions, that govern their understanding of the utterances and that the speakers/writers can be assumed to adapt their utterances to, emerge in the selection and coordination of extra-communicative actions in the performance of activities. Therefore, studies of information structure must be based on activity-embedded language use.

If there is anything one can learn from studying activity-embedded language use, it is that there is no simple relation between the speaker saying something and the listener doing something. What characterizes this language use is rather that the speaker/writer directs attention to information in the environment, which, based on particular goals, values and knowing how, encourages the listener/reader to act in certain ways. Whether or not the listener/reader acts as predicted, depends on whether the listener/reader share the goals, values and the knowing how that the relation between the information and the action relies on. The relation between linguistically conveyed information and extra-communicative action is based on an incomprehensibly large preparatory work of our forefathers, and nothing - nothing - can be achieved by language use alone. In other words, one becomes quite humble on behalf of language.

Therefore, I will limit myself to a simple and cautious instruction. The next time you select an utterance for information structure analysis, require that there are extra-communicative criteria for the understanding of the utterance. This could, in the long run, lead to a watershed in the linguistic description of information structure.

\section{References}

Borchmann, S., 2015. "Fordi man ved aldrig" - emne, fokus og kohærens i informativ udøversprogbrug. Skandinaviske Sprogstudier 6, 4, 17-106.

Borchmann, S., 2016. En funktionel semantik baseret på økologisk psykologi. NyS 50 - Nydansk sprogstudier. Frederiksberg, Dansk Sprognævn, 183-220.

Borchmann, S., 2018. Utterances as Tool-Mediated Specifications of Affordances: Ecological Pragmatics. Psychology of Language and Communication, 22.

Brentano, F., 1925. Vorstellung und Urteil, zwei Klassen. Psychologie vom empirischen Standpunkt. Leipzig, Felix Meiner, 38-82.

Bühler, K., 1965/1934. Sprachtheorie, die Darstellung der Sprache. Stuttgart, Gustav Fischer. 
Chafe, W., 1970. Meaning and the Structure of language. Chicago, The University of Chicago Press.

Chafe, W., 1976. Givenness, Contrastiveness, Defineteness, Subjects Topics, and Point of View. In: Li, C.N. (Ed.) Subject and Topic. London, Academic Press.

Chafe, W., 1994. Disourse, Consciousness, and Time, Chicago \& London, The University of Chicago Press.

Chomsky, N., 1965. Aspects of the Theory of Syntax. Cambridge, MIT Press

Clark, H., 1996. Using language. Cambridge, Cambridge University Press.

Cowley, S., 2009. Distributed language and dynamics. Pragmatics \& Cognition 17:3, 495-507.

Daneš, F. 1974. Functional sentence perspective and the organisation of text. In: Daneš, F. (Ed.), Papers on Functional Sentence Perspective. Academia, Publishing House of the Czechoslovak Academy of Sciences, Prag.

Dik, S., 1989. The Theory of Functional Grammar, part 1: The Structure of the Clause.

Dordrecht, Foris Publications.

Firbas, J., 1964. On defining theme in functional sentence analysis. Travaux Linguistiques de Prague. Prag, Académie tchécoslovaque des Sciences.

Firbas, J., 1974. Some aspects of the Czechoslovak approach to problems of functional sentence perspective. In: Daneš, F. (Ed.), Papers on Functional Sentence Perspective. Prag, Academia, Publishing House of the Czechoslovak Academy of Sciences.

Firbas, J., 1992. Functional sentence perspective in written and spoken communication. Cambridge, London University Press.

von der Gabelentz, G., 1869. Ideen zu einer vergleichenden Syntax. Zeitschrift für Völkerpsychologie und Sprachwissenschaft, 6. Berlin.

Garrod, S., 1995. Dinstinguishing between Explicit and Implicit Focus during Text Comprehension, In: Richeit, G. \& Habel, C. (Eds.), Focus and Coherence in Discourse Processing. Berlin, Walter de Gruyter.

Geluykens, R., 1999. It Taks Two to Cohere: The Collaborative Dimension of Topical Coherence in Conversation. In: Bublitz, W., Lenk, U. \& Ventola, E. (Eds.), Coherence in Spoken and Written Discourse. Pragmatics \& Beyond New Series, 63. Amsterdam, John Benjamins Publishing Company.

Gibson, J.J., 1986. The ecological approach to visual perception. New York, Psychology Press.

Givon, T., 1982. Logic vs Pragmatics, with Human Language as the Referee: Toward and Empirically Viable Epistemology. Journal of Pragmatics 6, 81-133. 
Givon, T., 1984. Topic Continuity in Discourse: A Quantative Cross-Language Study. Amsterdam/Philadelphia, John Benjamins Publishing Company.

Goodwin, C. \& Goodwin, M.H., 1998. Seeing as situated activity: Formulating planes. Engeström, Y. \& Middleton, D. (Eds.), Cognition and Communication at work. Cambridge, Cambridge University Press. 61-95.

Gundel, J.K. \& Fretheim, T., 2005. Topic And Focus. In: Horn, L.R. \& Ward, G. (Eds.), The handbook of pragmatics. Malden, MA, Blackweel Publishing.

Gundel, J.K., 2012. Pragmatics and information structure. In: Allen, K. \& Jaszczolt, M.M. (Eds.), The Cambridge Handbook of Pragmatics. Cambridge, Cambridge University Press.

Haberland, H., 2006. Thetic-categorial distinction. In: Brown, K. (Ed.), Encyclopedia of Language and Linguistics, 2nd edition 12, 676-677.

Hajicová, E. \& P. Sgall, 2004. Degrees of Contrast and the Topic-Focus Articulation. In: Steube, A. (Ed.), Information structure: Theoretical and Empricial aspects. Walter de Gruyter, Berlin/New York.

Halliday, M.A.K., 1967. Notes on transitivity and theme in English. Journal of linguistics. London.

Halliday, M.A.K. \& Hasan, R., 1976. Cohesion in English. London, Longman.

Halliday, M.A.K., 1978. Language as a Social Semiotic. London, Edward Arnold.

Halliday, M.A.K., 1998. An Introduction to Functional Grammar. London, Arnold.

Halliday, M.A.K., 2004. Introduction to functional grammar (3rd ed.). London, Arnold.

Halliday, M.A.K. \& Matthiessen, C.M.I.M., 2014. Halliday's Introducation to Functional Grammar. London, Routhledge, Taylor \& Francis Group.

Hansen, E. \& Heltoft, L., 2011. Grammatik over det danske sprog. Det Danske Sprog- og Litteraturselskab, Syddansk Universitetsforlag.

Harder, P., 2010. Meaning in Mind and Society. Berlin, De Gruyter Mouton.

Harder, P., 2016. Substance(s) and the rise and imposition of structure(s). Acta Linguistica Hafniensia, 48:1, 7-34

Haviland, S.E. \& Clark, H.H. 1977. Comprehension and the Given-New Contract. In: Freedle, R. (Ed.): Discourse Production and Comprehension. Norwood, New Jersey, Ablex Publishing Corporation.

Heritage, J., \& Clayman, S., 2010. Talk in Action: Interaction, Identities, and Institutions. WileyBlackwell, Oxford. 
Von Heusinger, K. 1999. Intonation and Information Structure. The Representation of Focus in Phonology and Semantics. Habilitationsschrift. Universität Konstanz.

Hodges, B.H., 2009. Ecological pragmatics: Values, dialogical arrays, complexity, and caring. Pragmatics \& Cognition, 17(3), 628-652.

Hodges, B.H., 2007. Good prospects: ecological and social perspectives on conforming, creating, and caring in conversation. Language Sciences 29, 584-604.

Hodges, B.H. \& Baron, R.M., 1992. Values as constraints on affordances: perceiving and acting properly. Journal for the Theory of Social Behaviour, 22, 263-294

Hutchins, E., 1995A. Cognition in the Wild. Cambridge, The MIT Press.

Hutchins, E. 1995B. How a Cockpit Remembers Its Speeds. Cognitive Science 19, 265-288.

Jackendoff, R. S. 1972. Semantics Interpretation in Generative Grammar. Cambridge, The MIT Press.

Klein, G., 1999. Sources of Power. How People Make Decisions. Cambridge, The MIT Press.

Krifka, M. \& Musan, R., 2012. Information structure: Overview and linguistic issues. Krifka, M. Musan, R. \& Klein, W. (Eds.) Expression of Cognitive Cathegories: Expression of Information Structure. Munchen, Walter de Gruyter.

Kristoffersen, J. F., Rasmussen, D.S.L. \& Mikkelsen, K. B., 2016. ja og der er masser af plads til jer og så skyd for helvede udefra - en pragmatisk analyse af fokus og emne i tetiske sætninger og imperativsætninger. Roskilde University. http://docplayer.dk/25132983-Ja-og-der-er-masser-af-plads-til-jer-og-saa-skyd-for-helvedeudefra.html

Kuno, S., 1972. Functional sentence perspective: A case study from Japanese and English. Linguistic Inquiry, 3, 269-320.

Kuroda, S.-Y., 1972. The categorical and the thetic judgment. Foundations of Language, 9, 153185.

Kuroda, S.-Y., 2005. Focusing on the Matter of Topic: A Study of Wa and Ga in Japanese. Journal of East Asian Linguistics, 14(1), 1-58.

Lambrecht, K., 1994. Information structure and sentence form. Cambridge, Cambridge University Press.

Levinson, S.C., 1979. Activity types and language. Linguistics, 17, 365-399.

Linell, P., 1982. The Written Language Bias in Linguistics. Studies in

Communication, 2. Linköping: Department of Communication Studies. 
Linell, P., 2004. The Written Language Bias in Linguistics: Its Nature, Origins and

Transformations. Routledge, London. ISBN 0-203-34276-3 Master e-book ISBN

Linell, P. 2010. Communicative Activity Types as Organisations in Discourses, and Discourses in Organisations. In: Tanskanen, S.-K., Helasvuo, M.-L., Johansson, M. \& Raitaniemi, M. (Eds.), Discourse in Interaction. Amsterdam, John Benjamins. 33-59.

Lyons, J., 1977. Semantics. Cambridge, Cambridge University Press.

Malinowski, B., 1969/1923. The Problem of Meaning in Primitive Languages. In: Ogden, C.K. \& Richards, I.A. (Eds.), The Meaning of Meaning: A Study of the Influence of Language upon Thought and of the Science of Symbolism. Eighth edition. New York, Harcourt, Brace \& World, 296-336.

Marty, A., 1940. Von den logisch begründeten Synsemantika beim Urteilsausdruck. Psyche und Sprachstruktur. Bern, A. Francke. 'is-pep

Mathesius, V., 1975/1961. A Functional Analysis of Present Day English on a General Linguistic Basis. The Hague/Paris, Mouton.

National Transportation Safety Board, 2007. Runway Overrun and Collision, Southwest Airlines Flight 1248, Boeing 737-7H4, N471WN, Chicago Midway International Airport, Chicago, Illinois, December 8, 2005. Aircraft Accident Report NTSB/AAR-07/06. Washington, DC.

Paul, H. 1898. Prinzipen der Sprachgeschichte. Halle A.S., Max Niemeyer.

Pedersen, S.B., 2012. Interactivity in health care: Bodies, values and dynamics. Language Sciences 32

Prince, E., 1981. Toward a Taxonomy of Given-New Information. In: Cole, P. (Ed.) Radical Pragmatics. New York, Academic Press.

Rasmussen, J., Pejtersen, A.M. \& Goodstein, L.P., 1993. Cognitive Systems Engineering. New York, John Wiley \& Sons, Inc.

Reed, E.S., 1996. Encountering the world. New York, NY: Oxford University Press.

Reinhart, T., 1982. Pragmatics and linguistics. Analysis of sentence topics. Philosophica 27, 53-94.

Reinhart, T., 1980. Conditions for Text Coherence, Poetics Today, vol. 1, nr. 4, Narratology II: The Fictional Text and the Reader, 161-180.

Rooth, M., 1985. Association with Focus. PhD Thesis, University of Massachusetts.

Rosengren, I., 1997. The thetic/categorical distinction revisited once more. Linguistics, 35, 439479. 
Sanford, A. \& Garrod, S.C., 1994. Selective Processing in Text Understanding. In: Gernsbacher, M. A. (Ed.), Handbook of psycholinguistics. San Diego, Academic Press.

Sasse, H.J., 1987. The thetic/categorical distinction revisited. Linguistics, 25, 511-580.

de Saussure, F., 1970/1916. Lingvistikkens object In: Madsen, P. (Ed.), Strukturalisme. En antologi. København, Rhodos.

de Saussure, F., 1964/1916. Cours de linguistique générale. Publié par Ch. Bally et A.Sechehaye. Paris: Payot.

Shannon, C. \& Weaver, W., 1998/1949. The Mathematical Theory of Communication. University of Illinois Press.

Stalnaker, R., 1974. Pragmatic presuppositions. In Munitz, M.K. \& Unger, P.K. (Eds.), Semantics and Philosophy. 197-214. New York, New York University Press.

Steffensen, S.V., 2012. Care and conversing in dialogical systems. Language Sciences 34, 513-531

Strawson, P.F., 1974. Subject and Predicate in Logic and Grammar. London, Methuen.

Talmy, L., 2000. Toward a cognitive semantics, Volume I: Concept Structuring Systems. Cambridge, The MIT Press.

Togeby, O., 2003. Fungerer denne sætning?. København, Gads Forlag.

Togeby, O., 1993. PRAXT-pragmatisk tekstteori. Århus, Aarhus Universitetsforlag

Tomasello, M., 2008. Origins of Human Communication. Cambridge, The MIT Press.

Thibault, P.J., 2011. First-Order Languaging Dynamics and Second-Order Language: The

Distributed Language View. Ecological Psychology 23, 210-245.

Ulbæk, I., 2013. Kohærens af anden orden. NyS Nydanske Sprogstudier, 45. København, Dansk Sprognævn.

Vallduví, E. \& M. Vilkuna, 1998. On rheme and kontrast. In: Culicover, P. \& L. McNally (Eds.), Syntax and semantics, the limits of syntax 29. Academic Press, London.

Vygotsky, L. S., 1978. Mind in Society. The Development of Higher Psychological Processes. Cambridge, Harvard University Pres.

Weil, H. 1978/1887. The Order of Words in the Ancient Languages compared with that of the Modern Languages. Amsterdam, John Benjamins B.V.

Wilson, A.D. \& Golonka, S., 2013. Embodied cognition is not what you think it is. Frontiers in Psychology, 4, 1-13. 
Wittgenstein, L., 1968/1953. Philosophische Untersuchungen, Philosophical investigations. Oxford, Basil Blackwell. 